\title{
Career Functions Performed by Mentors of Millennial Generation Entrepreneurs
}

\author{
Nathanael Moulson ${ }^{1}$, Anne Davis ${ }^{2}$ \\ ${ }^{1}$ The Department of Management and Economics, Royal Military College of Canada, Kingston, Canada \\ ${ }^{2}$ College of Management and Technology, Walden University, Minneapolis, USA
}

Email address:

Nathanael.Moulson@RMC.ca (N. Moulson), Anne.Davis@Waldenu.edu (A. Davis)

To cite this article:

Nathanael Moulson, Anne Davis. Career Functions Performed by Mentors of Millennial Generation Entrepreneurs. American Journal of Management Science and Engineering. Vol. 3, No. 5, 2018, pp. 69-75. doi: 10.11648/j.ajmse.20180305.15

Received: May 15, 2018; Accepted: October 17, 2018; Published: November 30, 2018

\begin{abstract}
Millennial generation entrepreneurs are showing a higher than average interest in starting new companies. This generation is key to economic success in Canada since the millennial generation comprises roughly $25 \%$ of the Canadian population. Mentors may make the difference between success and failure of these new ventures. This multiple case study explored 6 millennial generation small business owners participating in the Futurpreneur Canada mentoring program. Data included semistructured interviews with participants of the Futurpreneur mentoring program, experience profiles of these participants, and public information about the Futurpreneur program. The analysis of the data demonstrated that mentors provided career support by serving in the following roles: (a) advisor for entering new markets, (b) connector to experts, and (c) advisor on a business function. Insights from this study may help program designers, entrepreneurs, and mentors work together to enable entrepreneurs to develop their organizations and set them on the path to success.
\end{abstract}

Keywords: Entrepreneur Education, Millennial Generation, Mentoring, Canadian Small Business

\section{Introduction}

Entrepreneurs face numerous challenges when starting a new business. In Canada, only $63 \%$ of new businesses survive to the five-year mark while only $43 \%$ are still in operation after 10 years. [1] Despite these long odds, millennial generation entrepreneurs are taking on these challenges, but many of these founders lack the experience and competencies needed. [2-3] Mentors are one tool small business owners can use to navigate these challenges. [4] Little research exists on how millennial generation small business owners use mentors to improve their business performance. A Canadian entrepreneurship program targeting millennial generation was studied to explore how the successful entrepreneurs in the program used mentors to improve performance.

\section{Literature Review}

\subsection{Millennial Generation}

Millennials, those born between 1980 and 2000, are now the largest generation in both the United States and Canada. [5] The millennial generation includes over 76 million people in the United States and 6.9 million in Canada. [6-7] This generation is entering the workforce in an unfavorable employment environment where unemployment of younger adults is twice as great as the remainder of the population forcing over $25 \%$ of this generation to work in jobs they are overqualified for. $[1,8]$

The poor employment environment, coupled with what millennials desire from employment, is making entrepreneurship an attractive option for this generation. Buzza explored what millennials want from the workplace and found millennials were significantly more attracted to jobs offering work-life balance and job advancement was not a significant attractor. [9] Ferri-Reed found millennials require continuous feedback to understand how they are performing. [10] Additionally, Gursoy et al. found millennials desire work-life balance, good pay and benefits, the prospect of rapid career advancement, meaningful work experience, and a nurturing work environment. [11] The combination of these desired traits with an unfriendly employment environment is making entrepreneurship an 
attractive choice for millennials. Millennials are twice as interested in starting businesses as the rest of the population. [12]

\subsection{Adult Learning Theory}

Knowles noted that adults learn best when they are involved in the design of the learning, have someone providing support, and are in control of their learning. [13] Adult education programs should recognize adult learners are (a) are independent and capable of directing their learning, (b) want to apply their new knowledge immediately, (c) have a history of experiences that contribute to learning, (d) have learning needs that reflect their changing social roles, and (e) are intrinsically motivated. Werth and Werth indicated there is a generational shift underway in training environments around the world suggesting millennials dislike the lecture as a mode of instruction, desire a greater integration of technology in the classroom, and learn best when the teacher performs the role of facilitator rather than lecturer. [14] Werth and Werth went further noting a shift away from lecture-based learning to more interactive learning such as mentoring. [14] Mentoring practices, like other adult education methods, are most effective when the mentors recognize the characteristics of adult learners. [15] Mentoring has become one of the most common forms of professional development. [16-17]

\subsection{Entrepreneur Education}

Entrepreneur education programs have expanded exponentially over the past two decades. [18] Despite this growth, there remain many challenges with teaching this topic. Of note is the difficulty in making any single educational program relevant to all participants due to the diversity of owners and their businesses. Several researchers have found evidence that entrepreneurship is teachable. [19-20] Prabhu, et al. highlight the importance of entrepreneurial education to building confidence and Nabi et al., found entrepreneurship education in the first year of higher education develops entrepreneurial intentions. [21-22] Smith and Paton posited that traditional higher education institutions might not be well suited to educate entrepreneurs since course designers structure programs around specific silos of knowledge while entrepreneurs must think across disciplines and work with people with varied areas of expertise. [23] One effective alternative to these traditional educational programs may be learning on the job as entrepreneurs start their new businesses. [24] Cassar supported this alternative by showing experience improves an entrepreneur's ability to evaluate a business opportunity, enabling more realistic expectations, and increasing the likelihood of survival. [25]

\subsection{Mentoring and Mentoring Functions}

Understanding how adults learn may assist with the transfer of knowledge from mentor to protégé. A mentor is characterized by altruism, expertise, patience, and experience. [26] Leveraging these characteristics, the mentors educate through a variety of roles. [27] Mentoring, in the entrepreneurship context, enables novice entrepreneurs to learn as they operate. [28] Mentoring can lead to better business performance. [4, 29] Yusuf examined the effectiveness of support to new businesses and found outside assistance improved the chances of a start-up successfully transitioning to an operating firm. [30] Futurpreneur Canada offers a mentoring program, in line with these findings, by providing mentors who provide on the job support to entrepreneurs while they run their businesses. [31]

Mentors can provide three types of support to protégés: psychosocial support, career support, and role modeling. [32] St-Jean found the career mentoring function is the most significant regarding stimulating learning by the entrepreneur. [33] Career support mentoring functions are the most objective outcomes and include coaching, sponsorship, exposure, and protection. [34] McKevitt and Marshall noted that mentoring career support often manifests as teaching firm-specific knowledge such as legal, marketing, or business planning. [34] Terjesen and Sullivan demonstrated mentoring career functions eased the transition between corporate employment and the entrepreneurial life that, in turn, improved the chances of new business success. [35] Colakoglu and Gokus noted that new entrants want to make a real contribution and career functions provided by mentors can create opportunities for advancement. [36]

\section{Method}

The purpose of this qualitative case study was to explore how successful, millennial generation entrepreneurs used mentors to enhance company performance. The qualitative method was appropriate for this study since the task was to explore mentorship by engaging with individuals who experienced a mentoring relationship while they started a company. This method allowed participants to describe their experiences in sufficient detail to reveal themes that should provide insight into the research question.

A holistic, multiple case study design was implemented to explore the topic of how Canadian small business owners use mentors. Each small business owner represented a case within the broader context of the Futurpreneur mentoring program. A single case study is analogous to a single experiment, and whenever possible, researchers should use a multiple case study design. The study sample consisted of six Canadian millennial generation business owners identified as success stories by Futurpreneur Canada. Futurpreneur Canada is a not-for-profit organization that provides financing, mentoring, and support tools to small business owners aged 19-39. Futurpreneur Canada exists to improve the performance of small businesses, and the organization offers a mentoring program to support small business owners. [31] Futurpreneur Canada lends money to young entrepreneurs starting new businesses and assigns a business mentor to guide the entrepreneur through the first two years of running the business.

Following the case study protocol, data was collected from 
three different sources: the Futurpreneur Canada mentoring documents, the success story experience summaries, and semistructured interviews. We reviewed Futurpreneur Canada annual reports, the mentoring program description, and other documents authored by employees at Futurpreneur Canada. The interviews were conducted using the video conferencing software Skype and FaceTime. Deakin and Wakefield found potential interviewees often stated they did not have time to conduct a face-to-face interview, but when offered an online option, they were willing to participate. [37] A Skype interaction provides similar access to social and non-verbal cues as an onsite exchange. [38] Online interviews were of particular value to this study since the participants are busy entrepreneurs with unpredictable schedules and located in cities across Canada. Using online tools allowed adjustment to the entrepreneurs' schedules, accommodating such challenges as different time zones.

Once the data was collected, a thematic analysis of the codes from each case was performed. These themes enabled an interpretation of the data and a contrasting of the findings between cases and to existing literature. These themes were compared to past research on the topics of the millennial generation, entrepreneur education, and mentoring. The interpretations were shared with the participants, providing them an opportunity to comment on these interpretations and provide feedback being careful to rely on our interpretation of the data for conclusions. This member checking process improves the validity of the findings by improving the accuracy of the interpretations. [39]

\section{Results}

Based on the multiple sources of data used in this case study, it was identified that these mentors provided three career functions to their protégés. The career roles that emerged were (a) advisor for entering new markets, (b) connector to experts, and (c) advisor on a business function.

\subsection{Advisor for Entering New Markets}

The entrepreneurs used mentors to help connect them with members of the mentor's generation. In some cases, this meant the younger entrepreneur was using the older mentor to connect with the older generation while in other cases the mentor and the entrepreneur were of the same generation. In either of these cases, the entrepreneur leveraged the mentor's understanding of the generation to allow the entrepreneur to sell goods and services to this group. For example, Participant 4's mentor provided insight into the baby boomer generation who were the decision makers in the corporate market Participant 4 was attempting to penetrate. Through recommendations and introductions, Participant 4's mentor held open the door to his mentee as they entered a new market. Participant 4's experience was an example of a mentor/mentee relationship where the difference in generations was helpful. There were also examples where both parties were of the same generation, but the outcome of having the mentor as a valuable connection to a particular demographic proved valuable. Futurpreneur staff introduced Participant 2 to a potential mentor who was much older. Participant 2 decided this was not a good fit because his target market included younger people. Eventually, he found a mentor who, in his words "knew how to bring a hip new product into the city" citing the importance that his mentor understood the demographic the entrepreneur was targeting. Participant 2 added to this perspective in his experience profile where he stated, "Having a female perspective was constantly refreshing." This perspective, which was different from his, provided insight into his market. Having a perspective that differs from the entrepreneur's perspective can offer insight into new markets.

Through Participant 1's responses to the interview questions, she indicated having a mentor who could connect her to new markets was important. She described an instance where her mentor, who is part of a market she was trying to penetrate, visited her business and noticed several gaps in the experience for people like him. The entrepreneur adapted the business offering based on these recommendations and her sales improved. This positive outcome was a result of her mentor offering advice on how to attract people like himself. Similarly, Participant 5 found peer mentors were able to provide valuable feedback. He attributed this valuable feedback to the fact they are in his demographic, which is also his target market. Sometimes an entrepreneur can be too close to the product or service to see different ways to perceive different aspects of their target market. Having a mentor who can see things differently may enable the entrepreneur to tap into new markets.

\subsection{Connector to Experts}

While a mentor may not always be much older than the entrepreneur, the mentor must be more experienced than the mentor to bring credibility and value to the relationship. One way mentors exhibited their experience was through their vast network of connections. Most of the entrepreneurs used their mentors to make valuable connections in the community. Participant 6 described this when she said her mentor seemed to, "Know everyone in the business community." She explained how her mentor seemed to introduce her, "To his team of advisors" and he gave her access to them whenever she required their help. She felt this gave her many tools she would not have had without her mentor. Participant 1 indicated her mentor had, "A lot of connections so if he does not know how to handle an issue he will connect me with someone who does." Participant 2 cited, "The biggest impact, without a doubt, was her connections with people... the individuals she connected us to made the biggest difference." He stated his mentor was very popular in their operating area, and the mentor introduced him to many valuable people during the early stages of his company. He felt his mentor was very good at introducing him to people through email. The mentor would often know people who could use the product and use email to make the connection. Participant 4's mentor made connections similarly. She stated her mentor would, "Send 
out an email that he copies me on introducing what we do and then it is up to me to connect with the person and it is expected that I will connect, bring them some samples to see what they think."

This theme surrounding the connector to experts can be further refined into two strategies. The first was evident when the entrepreneur used the mentor's connections to provide advice and the second where the mentor leveraged their connections to drive business towards the entrepreneur. Participant 6 used her mentor to connect with individuals who could help her navigate through challenges related to running her business. Alternatively, Participant 2 and Participant 4 used their mentors to connect them to new customers. The overall strategy is to leverage the mentor's network, but these are two distinct uses of the network. This strategy is evident in the material provided on the Futurpreneur website. The website indicated one of the benefits entrepreneurs should expect from having a mentor is to enhance their business network. [31] A non-participant entrepreneur profiled on the Futurpreneur website indicated his "mentor brings not only strong business acumen, wisdom, and experience, but also connections and success from his own business." [31] Entrepreneurs can readily gain connections to experts through the establishment of a mentoring relationship.

\subsection{Advisor on a Business Function}

Several of the mentors provided their protégés with advice on specific business functions. For Participants 2, 3 and 4, the mentor performed the role an employee or consultant might otherwise. The mentors provided specific advice on marketing tactics and the development of a comprehensive marketing plan. In each of these cases, the fact the mentor had marketing experience was what drew the entrepreneur to the mentor in the first place. For Participant 2 this worked very well since his mentor, as he stated, "Forced us to make a one-year marketing plan." The mentor augmented this by prompting questions like how Participant 2 plans to thank customers. Participant 3 indicated her mentor, "has way more experience than I do in marketing." She noted her mentor reviewed her marketing plan and made suggestions for the use of social media. In her experience summary, Participant 3 stated her mentor was instrumental in helping her create a brand for her business.

Similar to Participants 2 and 3, Participant 4 acknowledged she needed help in marketing and sales and sought a mentor who could advise in these areas. Futurpreneur matched her with a sales professional who was not an entrepreneur. This mentor taught the mentee sales techniques by modeling the techniques. He followed this by encouraging Participant 4 to try the techniques on real clients while he supervised and provided feedback following the exercise. Through this hands-on training, this mentor taught Participant 4 how to be a better salesperson. In addition to this training, Participant 4's mentor recommended different marketing initiatives that, as Participant 4 describes, "Have become core parts of our business."
According to other stories highlighted on the Futurpreneur website, marketing advice is a popular benefit received from mentors. One entrepreneur highlighted on the Futurpreneur website stated their mentor's "Marketing background was a critical part of meeting our goal." [31] Participant 6 used her mentor for a different business function. She relied on her mentor to provide financial advice due to his background as an accountant. She described her mentor as her "financial strategist," indicating he played the role of the finance department for her company.

In each of these cases, the entrepreneurs used their mentor to make up for a deficiency in a specific business function. By selecting a mentor with a particular skill set, these entrepreneurs were able to strengthen their corporate knowledge and make better business decisions. They were able to achieve this improved capacity without paying for expensive advice in these critical business functions. The participants' experiences show using a mentor to play a specific role is a cost-effective way to improve the performance of a new company.

\section{Discussion}

The benefit of providing new connections and expanding a mentee's network is widely covered in the literature. $[4,40]$ However, we did not uncover any discussion of mentees using their mentors to connect with the mentor's generation. Using mentors as a connection to a new market seems natural. The fact the participants used their mentors to connect to a new market supports the premise of social penetration theory where relationships that offer more benefits than costs are more likely to continue. [41] In these cases, the mentee is benefiting by leveraging the mentor's knowledge of the mentor's generation to market to this group.

Existing literature supports the notion the participants in this study had about the valuable connections they made because of their mentor. Connections are part of creating a successful business and having a well-connected mentor is a shortcut to building a strong network. [42] Allen and Poteet found researchers present exposing a mentee to a new network as a career function of mentoring. [43] When Smith and Beasley studied how mentors can help entrepreneurs overcome obstacles, they found providing the entrepreneur with access to specialist advice through their networks was helpful. [40] The interviews with the participants validated these findings and supported the notion new entrepreneurs should seek to leverage the networks of their mentors to improve their chances of success.

Based on existing literature, mentors provide specific business advice. Some of the entrepreneurs relied heavily on their mentors for specific information and guidance that would otherwise be costly to obtain through hiring employees or paying consultants. Having a mentor provide specific advice is a beneficial outcome for new entrepreneurs who are, based on their novice status, likely to have many gaps in their knowledge. 
The experiences of the entrepreneurs studied in this multiple case study support Knowles' adult learning theory. [13] Smith and Beasley found that new entrepreneurs often lack general business skills and specialist knowledge. [40] Knowles recognized that adult learners are independent and are capable of directing their own learning. Creating an open forum to ask questions and seek advice capitalizes on the mentees' intrinsic motivation, which was another tenet of Knowles' (1973) adult learning theory. Through the career functions identified in this study, participants' mentors augmented shortages that the entrepreneurs had. Similar to the participants of past studies, the participants in this study indicated they benefited from the mentoring relationship. [33, 44].

\section{Recommendations for Further Research}

This group of participants described their mentoring experiences while their businesses operated successfully. Not all of the mentoring relationships were successful, but the businesses were. Researchers could conduct a similar case study using participants who were not successful. These participants might provide additional recommendations for how entrepreneurs can use mentors to succeed by highlighting what their mentors did or did not do. These findings would contribute to building the body of knowledge around mentoring entrepreneurs.

The participants in this study began their entrepreneurial journey with the help of Futurpreneur. Futurpreneur was responsible for coordinating the mentoring relationship in the early stages. Researchers should consider exploring the mentoring experiences of entrepreneurs who worked with different organizations. In a multiple case study design, the researchers could compare the outcomes of the different programs to expose the critical aspects of such programs. Future researchers might also want to study those entrepreneurs who have chosen not to pursue a mentoring relationship.

One theme that emerged during our analysis was entrepreneurs benefited from insight into their mentor's demographic. For some of the entrepreneurs, this proved critical to their success, as the mentor was able to make important connections and advise on the best way to penetrate a market. Researchers should consider exploring the role this characteristic plays in entrepreneurial mentoring experiences. Researchers might explore the question: how much economic benefit do entrepreneurs experience when the mentor is part of the target market? Researchers could also examine the question: what percentage of mentoring relationships succeed when the mentor is not part of the target demographic? Based on the responses of the participants and the lack of research in this area, this could be a valuable contribution to entrepreneurial mentoring literature.

Finally, the specific nature of this case study limited the generalizability of the findings. The design requires the reader to assess the generalizability of the findings. Researchers could carry out a study of the mentoring experiences of millennial generation entrepreneurs using a more generalizable design. This could produce findings that have a broader impact than those found here.

\section{Conclusions}

The three career functions identified in this case study may help new small business owners determine what they should expect from their mentor. This may also assist entrepreneurs in evaluating what capabilities and experience they should look for in a mentor. Rather than just meeting with a mentor without expectations, new entrepreneurs can refer to these findings to establish what their mentor can do for them as they build their new business. This may require new entrepreneurs to realistically assess their capabilities and note their weaknesses so that they can use a mentor to augment those identified weaknesses.

These findings are also relevant to those developing mentoring programs for millennial generation entrepreneurs and entrepreneurs in general. By identifying the roles mentors play, designers can advise mentors on how to work with their mentees. The program designers can develop training programs that help mentors be effective in their roles and to look for opportunities to assist their mentors. Mentoring organizations, like Futurpreneur, should advise the entrepreneur of the roles their mentor could play in their success. Mentoring organizations should incorporate these lessons into training programs for entrepreneurs and mentors. Mentors should seek out further education to become more proficient in these roles.

These findings are relevant to the practice of mentoring. Mentors may use these roles as a guide for becoming better in their role. For example, they might invest in learning more about how to write an effective introduction email to improve the value they offer to the mentee. Further, they might better see how their experience can augment that of their mentee and offer specific guidance on a business function.

Educating entrepreneurs is a complex and ever-changing challenge that will require continuous adaptation and improvement to improve the performance of new entrepreneurs and the firms they create. These findings contribute to refining the educational offering to entrepreneurs by highlighting successful entrepreneurs and uncovering their reflections regarding mentoring relationships. The findings in this study have the potential to pay significant dividends far into the future if millennial generation entrepreneurs, program designers, and mentors can learn from the findings.

Mentoring organizations such as Futurpreneur Canada can apply these findings to their program development and delivery methods. As entrepreneurs and mentoring organizations improve their relationship, their increased performance should improve the performance of new businesses and increase the otherwise poor success rate. 
Stronger, more innovative companies will build healthier communities and enable entrepreneurs to contribute to solving problems.

\section{References}

[1] Archambault, R., and Song, M. (2018) 'Canadian new firms: Birth and survival rates over the period 2002-2014', Ottawa, ON: Innovation, Science and Economic Development Canada, Small Business Branch.

[2] Intuit Canada. (2013) 'Startup Generation: How millennials are remaking the Canadian economy' [online] http://blog.intuit.ca (Accessed 12 July, 2015).

[3] Gudmundsson, S. V., and Lechner, C. (2013) 'Cognitive biases, organization, and entrepreneurial firm survival', European Management Journal, Vol. 31, pp. 278-294.

[4] St-Jean, E., Radu-Lefebvre, M., \& Mathieu, C. (2018). Can less be more? Mentoring functions, learning goal orientation, and novice entrepreneurs' self-efficacy. International Journal of Entrepreneurial Behavior \& Research, 24(1), 2-21.

[5] Caraher, L. (2016). Millennials \& Management: The Essential Guide to Making it Work at Work. Routledge.

[6] Statistics Canada (2017, December 27). Population estimates on July 1st, 2017 by age and sex.

[7] United States Census Bureau (2018). 2017 National Population Projections Datasets.

[8] International Labour Organisation (2017). World employment social outlook: Trends 2017.

[9] Buzza, J. S. (2017). Are You Living to Work or Working to Live? What Millennials Want in the Workplace. Journal of Human Resources Management and Labor Studies, 5(2).

[10] Ferri-Reed, J. (2014). Millennializing the Workplace. The Journal for Quality and Participation; Cincinnati, 37(1), 1314.

[11] Gursoy, D., Chi, C. G.-Q., and Karadag, E. (2013) 'Generational differences in work values and attitudes among frontline and service contact employees', International Journal of Hospitality Management, Vol. 32, pp. 40-48.

[12] BNP Paribas (2016). Global entrepreneurs Report 2016.

[13] Knowles, M. (1973) The Adult Learner: A Neglected Species. Gulf, Houston, TX.

[14] Werth, E. P., and Werth, L. (2011) 'Effective training for Millennial students', Adult Learning, Vol. 22, pp. 12-19.

[15] Muir, D. (2014) 'Mentoring and leader identity development: A case study', Human Resource Development Quarterly, Vol. 25, pp. 349-379.

[16] Zepeda, S., Parylo, O., and Bengston, E. (2013) 'Analyzing principal professional development through the lens of adult learning theory', Professional Development in Education, Vol. 40, pp. 295-315.

[17] Leslie, H., and Johnson-Leslie, N. (2014), 'Technology mentoring: A model for professional development' in 2014 Society for Information Technology \& Teacher Education
International Conference Proceedings, SITE, Las Vegas, NV.

[18] Nabi, G., Liñán, F., Fayolle, A., Krueger, N., \& Walmsley, A. (2017). The Impact of Entrepreneurship Education in Higher Education: A Systematic Review and Research Agenda. Academy of Management Learning \& Education, 16(2), 277299.

[19] McKenzie, D., and Woodruff, C. (2014) 'What are we learning from business training and entrepreneurship evaluations around the developing world?', The World Bank Research Observer, Vol. 29, pp. 48-82.

[20] Rideout, E. C., and Gray, D. O. (2013) 'Does entrepreneurship education really work? A review and methodological critique of the empirical literature on the effects of university-based entrepreneurship education', Journal of Small Business Management, Vol. 51, pp. 329-351.

[21] Prabhu, V. P., McGuire, S. J., Kwong, K. K., Zhang, Y., \& Ilyinsky, A. (2017). Social Entrepreneurship among Millennials: A Three-Country Comparative Study. Australian Academy of Accounting and Finance Review, 2(4), 323-353.

[22] Nabi, G., Walmsley, A., Liñán, F., Akhtar, I., \& Neame, C. (2018). Does entrepreneurship education in the first year of higher education develop entrepreneurial intentions? The role of learning and inspiration. Studies in Higher Education, 43(3), 452-467.

[23] Smith, A., and Paton, R. (2011) 'Delivering enterprise: A collaborative international approach to the development, implementation and assessment of entrepreneurship', International Journal of Entrepreneurial Behavior \& Research, Vol. 17, pp. 104-118.

[24] Lorz, M., Mueller, S., and Volery, T. (2013) 'Entrepreneurship education: A systematic review of the methods in impact studies', Journal of Enterprising Culture, Vol. 21, pp. 123151.

[25] Cassar, G. (2014). 'Industry and startup experience on entrepreneur forecast performance in new firms', Journal of Business Venturing, Vol. 29, pp. 137-151.

[26] Waljee, J. F., Chopra, V., \& Saint, S. (2018). Mentoring Millennials. JAMA, 319(15), 1547-1548.

[27] Moulson, N. and Davis, A. (2016). How millennial generation entrepreneurs use mentors to improve performance. ICIE 2016 Proceedings of the 4th International Conference on Innovation and Entrepreneurship: ICIE2016. Academic conferences and publishing limited.

[28] St-Jean, E., and Audet, J. (2012) 'The role of mentoring in the learning development of the novice entrepreneur', International Entrepreneurship and Management Journal, Vol. 8, pp. 119-140.

[29] Rigg, C., and O'Dwyer, B. (2012) 'Becoming an entrepreneur: Researching the role of mentors in identity construction', Education + Training, Vol. 54, pp. 319-329.

[30] Yusuf, J. E. (2014) 'Impact of start-up support through guided preparation', Journal of Entrepreneurship and Public Policy, Vol. 3, pp. 72-95.

[31] Futurpreneur Canada (2018). [online] http://www.futurpreneur.ca. 
[32] Chun, J. U., Sosik, J. J., and Yun, N. Y. (2012) 'A longitudinal study of mentor and protégé outcomes in formal mentoring relationships', Journal of Organizational Behavior, Vol. 33, pp. 1071-1094.

[33] St-Jean, E. (2012) "Mentoring as professional development for novice entrepreneurs: Maximizing the learning', International Journal of Training and Development, Vol. 16, pp. 200-216.

[34] McKevitt, D., \& Marshall, D. (2015). The legitimacy of entrepreneurial mentoring. International Journal of Entrepreneurial Behaviour \& Research; Bradford, 21(2), 263280.

[35] Terjesen, S., and Sullivan, S. E. (2011) 'The role of developmental relationships in the transition to entrepreneurship: A qualitative study and agenda for future research', Career Development International, Vol. 16, pp. 482-506.

[36] Colakoglu, S. N., and Gokus, O. (2015) 'Mentoring functions' relationship with socialization facets and stages: A conceptual framework', Journal of Organizational Culture, Communications and Conflict, Vol. 19 No. 2, pp. 1-13.

[37] Deakin, H., and Wakefield, K. (2013) 'Skype interviewing: Reflections of two PhD researchers', Qualitative Research, Vol. 14, pp. 603-616.
[38] Janghorban, R., Roudsari, R. L., \& Taghipour, A. (2014). Skype interviewing: The new generation of online synchronous interview in qualitative research. International Journal of Qualitative Studies on Health and Well-Being, 9.

[39] Koelsch, L. E. (2013) 'Reconceptualizing the member check interview', International Journal of Qualitative Methods, Vol. 12, pp. $168-179$.

[40] Smith, K., and Beasley, M. (2011) 'Graduate entrepreneurs: Intentions, barriers and solutions', Education + Training, Vol. 53, pp. 722-740.

[41] Altman, I., and Taylor, D. A. (1973) Social Penetration: The Development of Interpersonal Relationships, Holt, Rinehart \& Winston, New York.

[42] Stam, W., Arzlanian, S., and Elfring, T. (2014) 'Social capital of entrepreneurs and small firm performance: A meta-analysis of contextual and methodological moderators', Journal of Business Venturing, Vol. 29, pp. 152-173.

[43] Allen, T. D., \& Poteet, M. L. (2011). Enhancing Our Knowledge of Mentoring With a Person-Centric Approach. Industrial and Organizational Psychology, 4(1), 126-130.

[44] Gupta, M. P., and Asthana, A. (2014) 'Innovation, incubation and entrepreneurship: A new approach', International Journal of Research in Finance and Marketing, Vol. 4, pp. 14-22. 